\title{
Article
}

\section{Clinical Significance of Tumor-Infiltrating Conventional and Plasmacytoid Dendritic Cells in Pancreatic Ductal Adenocarcinoma}

\author{
Ioana Plesca ${ }^{1,+}$, Iva Benešová ${ }^{1,+}$, Carolin Beer ${ }^{1}$, Ulrich Sommer ${ }^{2}$, Luise Müller ${ }^{1}{ }^{\mathbb{D}}$, Rebekka Wehner ${ }^{1,3,4}$, \\ Max Heiduk 3,4,5, Daniela Aust 2,3,4, Gustavo Baretton 2,3,4, Michael P Bachmann 3,4,6,7 (D, Anja Feldmann 7 ,

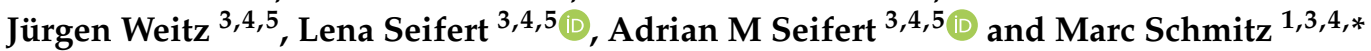

Citation: Plesca, I.; Benešová, I.; Beer, C.; Sommer, U.; Müller, L.; Wehner,

R.; Heiduk, M.; Aust, D.; Baretton, G.; Bachmann, M.P.; et al. Clinical Significance of Tumor-Infiltrating Conventional and Plasmacytoid Dendritic Cells in Pancreatic Ductal Adenocarcinoma. Cancers 2022, 14 , 1216. https://doi.org/10.3390/ cancers14051216

Academic Editors: Brian A. Boone and Tim D. Eubank

Received: 27 January 2022

Accepted: 22 February 2022

Published: 26 February 2022

Publisher's Note: MDPI stays neutral with regard to jurisdictional claims in published maps and institutional affiliations.

Copyright: (C) 2022 by the authors. Licensee MDPI, Basel, Switzerland. This article is an open access article distributed under the terms and conditions of the Creative Commons Attribution (CC BY) license (https:// creativecommons.org/licenses/by/ $4.0 /)$.
1 Institute of Immunology, Faculty of Medicine Carl Gustav Carus, TU Dresden, Fetscherstraße 74, 01307 Dresden, Germany; ioana-madalina.plesca@tu-dresden.de (I.P.); benesova.ivka@seznam.cz (I.B.); carolinbeer95@gmx.de (C.B.); luise.mueller1@tu-dresden.de (L.M.); rebekka.wehner@tu-dresden.de (R.W.)

2 Institute of Pathology, University Hospital Carl Gustav Carus, TU Dresden, Fetscherstraße 74, 01307 Dresden, Germany; ulrich.sommer2@uniklinikum-dresden.de (U.S.); daniela.aust@uniklinikum-dresden.de (D.A.); gustavo.baretton@uniklinikum-dresden.de (G.B.)

3 National Center for Tumor Diseases (NCT), University Hospital Carl Gustav Carus, TU Dresden, Fetscherstraße 74,01307 Dresden, Germany; max.heiduk@uniklinikum-dresden.de (M.H.); m.bachmann@hzdr.de (M.P.B.); juergen.weitz@uniklinikum-dresden.de (J.W.);

lena.seifert@uniklinikum-dresden.de (L.S.); adrian.seifert@uniklinikum-dresden.de (A.M.S.)

4 German Cancer Consortium (DKTK), Partner Site Dresden and German Cancer Research Center (DKFZ), Im Neuenheimer Feld 280, 69120 Heidelberg, Germany

5 Department of Visceral, Thoracic and Vascular Surgery, University Hospital Carl Gustav Carus, TU Dresden, Fetscherstraße 74, 01307 Dresden, Germany

6 Tumor Immunology, University Cancer Center (UCC), University Hospital Carl Gustav Carus, TU Dresden, Fetscherstraße 74, 01307 Dresden, Germany

7 Department of Radioimmunology, Institute of Radiopharmaceutical Cancer Research, Helmholtz Center Dresden-Rossendorf, Bautzener Straße 400, 01328 Dresden, Germany; a.feldmann@hzdr.de

* Correspondence: marc.schmitz@tu-dresden.de; Tel.: +49-351-458-6501

+ These authors contributed equally to this work.

Simple Summary: The tumor immune contexture plays a pivotal role for the clinical outcome of cancer patients and the efficacy of various treatment modalities. Dendritic cells (DCs) represent a major component of the tumor immune architecture that can either efficiently promote antitumor immunity or contribute to immunosuppression. Here, we investigated the frequency, spatial organization, and clinical significance of tumor-infiltrating conventional DCs type 1 (cDC1s) and type 2 (cDC2s) and plasmacytoid DCs (pDCs) in pancreatic ductal adenocarcinoma (PDAC). A higher frequency of whole tumor area (WTA)- and tumor stroma (TS)-infiltrating CDC1s, and of intraepithelial tumor-infiltrating cDC2s, was significantly associated with improved survival. Furthermore, a higher density of both WTA- and TS-infiltrating cDC1s and pDCs emerged as an independent prognostic factor for better survival. These results provide evidence that tumor-infiltrating DCs are associated with survival of PDAC patients and may support the design of novel DC-based immunotherapeutic strategies.

Abstract: Dendritic cells (DCs) play a key role in the orchestration of antitumor immunity. Activated DCs efficiently enhance antitumor effects mediated by natural killer cells and T lymphocytes. Conversely, tolerogenic DCs essentially contribute to an immunosuppressive tumor microenvironment. Thus, DCs can profoundly influence tumor progression and clinical outcome of tumor patients. To gain novel insights into the role of human DCs in pancreatic ductal adenocarcinoma (PDAC), we explored the frequency, spatial organization, and clinical significance of conventional DCs type 1 (cDC1s) and type 2 (cDC2s) and plasmacytoid DCs (pDCs) in primary PDAC tissues. A higher density of whole tumor area (WTA)- and tumor stroma (TS)-infiltrating cDC1s was significantly associated with better disease-free survival (DFS). In addition, an increased frequency of intraepithelial tumor-infiltrating cDC2s was linked to better DFS and overall survival (OS). Furthermore, an increased density of WTA- and TS-infiltrating pDCs tended to improve DFS. Moreover, a higher 
frequency of WTA- and TS-infiltrating CDC1s and pDCs emerged as an independent prognostic factor for better DFS and OS. These findings indicate that tumor-infiltrating DCs can significantly influence the clinical outcome of PDAC patients and may contribute to the design of novel treatment options that target PDAC-infiltrating DCs.

Keywords: pancreatic cancer; dendritic cells; tumor microenvironment; neoadjuvant chemotherapy

\section{Introduction}

Pancreatic ductal adenocarcinoma (PDAC) is one of the most lethal cancers with a 5-year overall survival (OS) of $10 \%$ [1]. This very poor prognosis is caused by late disease detection, the absence of suitable biomarkers [2], and insufficient efficacy of current treatment options [3,4]. Despite the success of immunotherapy across solid tumors [5], the favorable outcome of this treatment modality remains limited in PDAC patients, with primary resection and chemotherapy still being the current standards of care $[3,4,6]$. Two of the main limitations of immunotherapy in PDAC patients are the mechanical barrier of the tumor surroundings, as well as the presence of immune cell populations with a predominantly immunosuppressive phenotype [3,7].

Desmoplasia, a characteristic hallmark of PDAC, is one of the major tumor escape mechanisms caused by activated pancreatic stellate cells (PSCs). These cells are the main source of fibrosis, which creates the mechanical barrier and, therefore, may hinder immune cell infiltration and may limit drug delivery. Furthermore, PSC's proximity to cancer cells promotes tumor growth, invasion, and metastasis formation [8-10]. Another typical feature of PDAC is the immunosuppressive tumor microenvironment (TME) that is supported by PSCs through the secretion of cytokines, such as interleukin (IL)-10 and transforming growth factor (TGF)- $\beta[9,11]$, and chemokines that attract regulatory T cells (Tregs) [12]. In addition, PSCs can produce galectin-1, which limits the cytotoxic properties of CD8 ${ }^{+} \mathrm{T}$ cells and promotes the differentiation of $\mathrm{CD}^{+} \mathrm{T}$ cells toward a T-helper (Th) 2 phenotype $[9,11]$. For these reasons, the TME of PDAC patients consists mainly of regulatory immune cells, such as Tregs, tumor-associated macrophages (TAMs) with dominant M2 phenotype, myeloid-derived suppressor cells (MDSCs), and immunosuppressive cytokines [7,13].

Dendritic cells (DCs) are professional antigen-presenting cells that play a critical role in the induction and maintenance of antitumor immunity. Due to their functional properties, DCs may profoundly influence tumor progression and the clinical outcome of cancer patients. Conventional DCs type 1 (cDC1s) and type 2 (cDC2s), and plasmacytoid DCs (pDCs) represent major subsets of human blood DCs that have been detected in various tumor entities. Human cDC1s characteristically express CD141 (BDCA-3), XCR1, and CLEC9A [14]. They display an extraordinary capacity to cross-present antigens and induce effective cytotoxic T lymphocyte (CTL) responses. In addition, activated $\mathrm{CDC} 1 \mathrm{~s}$ can produce significant amounts of IL-12 that favors the polarization of naïve $\mathrm{CD} 4^{+} \mathrm{T}$ lymphocytes into Th1 cells and promotes the cytokine release and cytotoxic capacity of natural killer (NK) cells [14-17]. When evaluating the potential clinical relevance of cDC1s, it has been reported that a higher expression of a cDC1-specific gene signature is correlated with favorable disease-free survival (DFS) of breast cancer patients [18]. Furthermore, higher expressions of cDC1-associated gene signatures were significantly associated with prolonged OS in patients with breast cancer, colorectal cancer, head and neck squamous cell carcinoma (HNSCC), lung adenocarcinoma, skin cutaneous melanoma, and ovarian cancer [19-22]. Moreover, a high frequency of melanoma-infiltrating $\mathrm{CD} 40^{+} \mathrm{CDC} 1 \mathrm{~s}$ predicted improved OS [23].

Identification of human cDC2s is based on high expression of various molecules, primarily CD1c and CLEC10A [14]. CDC2s display an extraordinary capacity to present MHC-II-associated antigens to $\mathrm{CD} 4^{+} \mathrm{T}$ lymphocytes and to promote the polarization of naïve $\mathrm{CD} 4^{+} \mathrm{T}$ cells into Th1, Th2, and Th17 cells. Activated cDC2s secrete large amounts of 
various cytokines, including tumor necrosis factor (TNF)- $\alpha$, IL-1, IL-6, and IL-12 [24,25]. Higher expression of specific gene signatures for $\mathrm{CDC} 2 \mathrm{~s}$ was linked to better prognosis of patients with HNSCC, invasive breast carcinoma, lung adenocarcinoma, and skin cutaneous metastatic melanoma [20]. Conversely, a higher frequency of tumor-associated cDC2s was correlated with reduced OS in non-small cell lung cancer [26] and worse progression-free survival (PFS) of melanoma patients [23].

Human pDCs are mainly characterized by the expression of CD123, CD303 (BDCA-2), and CD304 (BDCA-4) [14]. pDCs present antigens with lower efficacy in comparison to cDCs, however, they are main producers of type I interferon upon stimulation. Interestingly, pDCs can directly kill cancer cells [27-29]. Enhanced expression of pDC-specific genes was associated with prolonged OS in HNSCC, papillary renal cell carcinoma, and lung adenocarcinoma [20]. Moreover, high levels of tumor-infiltrating $\mathrm{CD}^{+} 6^{+} \mathrm{pDC}$ s predicted prolonged PFS of melanoma patients [23]. More recently, we have shown that a higher density of tumor-associated pDCs is linked to improved PFS and OS of colon cancer patients [30]. In contrast, an enhanced frequency of tumor-infiltrating $\mathrm{pDC}$ s was associated with poor prognosis in breast cancer, hepatocellular cancer, melanoma, and ovarian cancer [31-34].

Previous studies have mainly explored the frequency of blood-circulating CDCs and pDCs and their association with clinicopathological characteristics of pancreatic cancer patients [35-37]. However, little is known about the potential clinical role of distinct PDACinfiltrating human DC subsets. Here, we explored the density and spatial organization of PDAC-associated cDC1s, cDC2s, and pDCs by utilizing multiplex immunohistochemistry (mIHC). In addition, the frequency of tumor-infiltrating DC subsets was linked to the clinicopathological characteristics of PDAC patients to gain novel insights into their clinical relevance. Additionally, we evaluated the influence of neoadjuvant chemotherapy on the frequency of the PDAC-associated DC subsets.

\section{Materials and Methods}

\subsection{Patient Samples}

This is a retrospective study consisting of 58 PDAC patients treated with either neoadjuvant therapy or primary resection at the Department of Visceral, Thoracic, and Vascular Surgery of the University Hospital Carl Gustav Carus of Dresden between 2008 and 2015. This study received the approval of the institutional review board of the Faculty of Medicine of the TU Dresden (No EK446112017). Patients gave their written informed consent to participate in the study. Serial sections of formalin-fixed paraffin-embedded (FFPE) tumor tissues were stained with hematoxylin and eosin (H\&E) for histologic assessment by an experienced pathologist. The clinical stage was determined by utilizing the pathological tumor-node-metastasis (pTNM) classification of the Union for International Cancer Control [38]. Table 1 summarizes the clinicopathological characteristics of PDAC patients. 
Table 1. Clinicopathologic characteristics of pancreatic ductal adenocarcinoma (PDAC) patients.

\begin{tabular}{cc}
\hline Age & $\begin{array}{c}n=58 \\
n(\%)\end{array}$ \\
Median (Range) \\
Gender \\
Male & $67.14(47-79)$ \\
Female & $30(52)$ \\
pT Stage & $28(48)$ \\
1 & \\
2 & $5(9)$ \\
3 & $33(57)$ \\
pN Stage & $20(34)$ \\
0 & $35(60)$ \\
1 & $23(40)$ \\
pM Stage & $58(100)$ \\
0 & $8(14)$ \\
UICC Stage & $50(86)$ \\
I & \\
II & $21(36)$ \\
Yes & $37(64)$ \\
No &
\end{tabular}

Abbreviations: pT: pathological tumor, pN: pathological node, pM: pathological metastasis, UICC: Union for International Cancer Control.

\subsection{Classical Immunohistochemistry}

We conducted immunohistochemical stainings of the BDCA-2 molecule to investigate the presence, localization, and density of pDCs in the PDAC tissues of 58 patients as described previously [30]. Briefly, the FFPE tissue blocks, sectioned at a thickness of 3$5 \mu \mathrm{m}$, were first deparaffinized, rehydrated, and exposed to heat-induced antigen retrieval. Once preparation was completed, the samples were incubated with a goat anti-BDCA-2 antibody (1:200, polyclonal, R\&D Systems, Minneapolis, MN, USA) overnight at $4{ }^{\circ} \mathrm{C}$. A bridging step, consisting of a $10 \mathrm{~min}$ incubation with a mouse anti-goat antibody solution (Thermo Fisher Scientific, Rockford, IL, USA), preceded the labeling and visualization of the BDCA-2 ${ }^{+}$pDCs by using the alkaline phosphatase-based EnVision detection system (Dako, Glostrup, Denmark). At the end, all tissue slides were counterstained with Mayer's hematoxylin (Merck, Darmstadt, Germany) and coverslipped with Aquatex mounting agent (Merck).

\subsection{Multiplex Immunohistochemistry}

To determine the presence, localization, and frequency of PDAC-associated CDC1s and $\mathrm{CDC} 2 \mathrm{~s}$, we performed mIHC stainings in 40 tumor specimens. For this, we employed the Ventana Discovery Ultra Instrument (Roche, Basel, Switzerland) and the Opal multiplex reagents (Akoya Biosciences, Menlo Park, CA, USA) together with the Vectra 3 automated quantitative pathology imaging system (Akoya Biosciences). As for the classical immunohistochemical stainings, the samples were firstly prepared by deparaffinization and heat-mediated antigen retrieval using the cell conditioning 1 solution (Roche). Then, incubation of a primary antibody and a corresponding secondary antibody (OmniMap anti-mouse, anti-rabbit, or anti-mouse-HQ, ready-to-use, all from Roche) followed for $32 \mathrm{~min}$ and $12 \mathrm{~min}$, respectively. In the case of the anti-mouse-HQ polymer, anti-HQ-HRP solution (Roche) was applied for another $12 \mathrm{~min}$. After that, incubation with one of the tyramide signal amplification fluorophores (Opal 520, 540, 620, and 650, all from Akoya Biosciences) took place for $8 \mathrm{~min}$. Heat treatment followed for $24 \mathrm{~min}$ to remove the primary and secondary antibodies. All these steps (excluding initial preparation) were repeated for each primary antibody in the panel, namely anti-CD1c (1:50, clone 2F4, Novus 
Biologicals, Littleton, Colorado, USA), anti-CLEC9A (1:100, clone EPR22324, Abcam, Cambridge, UK), anti-CLEC10A (1:75, polyclonal, Human Protein Atlas, Bromma, Sweden), and anti-PanCK (prediluted, clone AE1/AE3/PCK26, Roche). Finally, spectral DAPI (Akoya Biosciences) was added to the slides to counterstain the nuclei and a fluoromount medium (SouthernBiotech, Birmingham, Alabama, USA) was used for coverslipping.

\subsection{Quantification of PDAC-Infiltrating $c D C 1 s, c D C 2 s$, and $p D C s$}

All stained sections were whole scanned $(\times 100$ magnification) using the Vectra 3 automated quantitative pathology imaging system. The tumor-containing areas were marked in the Phenochart ${ }^{\mathrm{TM}}$ software (Akoya Biosciences), following the delineation performed by an experienced pathologist in serial H\&E slides. Then, a proportion of $25-50 \%$ of these tumor-containing regions was scanned $(\times 200$ magnification) for all patient slides for subsequent analysis. For the classical immunohistochemical stainings, positively stained pDCs were counted using the ImageJ software. These raw counts were used to determine the mean value, which was then converted into cell density. The analysis of mIHC stainings was performed using the inForm software (Akoya Biosciences). Following spectral unmixing, a semi-automatic approach was employed to teach the inForm software to segment the tissue areas (intraepithelial $\mathrm{PanCK}^{+}$tumor region, stromal region, and non-tissue areas), delineate the cells, and phenotype them. For all analyses, we defined and used the whole tumor area (WTA) as the entire tumor region comprising both the intraepithelial tumor (IET) area and the tumor stroma (TS) area. Finally, the reliability of each algorithm was tested on a validation set of MSIs drawn from all patients, before applying them to the entire cohort.

\subsection{Statistical Analysis}

Mann-Whitney $U$ test was performed to investigate the difference in DCs density at different tumor stages and for distinct therapy regimens, while the paired Wilcoxon test was used to compare DC frequencies between tumor localizations. Kaplan-Meier survival curves were utilized to visualize the differences in OS and DFS. OS was defined as the time period between surgery and death. DFS represents the time interval between surgery and disease recurrence. The patients were stratified into terciles (high, medium, and low infiltration), and only the high and low groups were compared. The significance was analyzed by log-rank test. A Cox proportional hazards regression model was implemented to explore the hazard ratio (HR) of DC infiltration in combination with several clinicopathological characteristics. Throughout the manuscript, the results are presented as mean value \pm the standard error of the mean. All statistical analyses were performed using the R software, and values of $p \leq 0.05$ were considered significant.

\section{Results}

\section{1. $c D C 1 s, c D C 2 s$, and $p D C$ Infiltrate PDAC}

To evaluate the role of three major human blood DC subsets in PDAC, we investigated the presence and density of cDC1s, cDC2s, and pDCs in tissue specimens from PDAC patients with different clinicopathological characteristics (Table 1). The three DC subsets were detectable in all PDAC samples at varying frequencies (Figure 1A-D).

As depicted in Figure $2 \mathrm{~A}-\mathrm{C}, \mathrm{cDC} 1 \mathrm{~s}$ were the most abundant DC subset in the WTA $\left(9.84 \pm 1.16 \mathrm{cDC} 1 \mathrm{~s} / \mathrm{mm}^{2}\right)$ in comparison to cDC2s $\left(2.98 \pm 0.597 \mathrm{cDC} 2 \mathrm{~s} / \mathrm{mm}^{2}\right)$ and $\mathrm{pDCs}$ $\left(6.28 \pm 0.917 \mathrm{pDCs} / \mathrm{mm}^{2}\right)$. In addition, we observed a significantly higher density of $\mathrm{cDC} 1 \mathrm{~s}$ $\left(12.6 \pm 1.62 \mathrm{cDC} 1 \mathrm{~s} / \mathrm{mm}^{2}\right), \mathrm{cDC} 2 \mathrm{~s}\left(3.35 \pm 0.662 \mathrm{cDC} 2 \mathrm{~s} / \mathrm{mm}^{2}\right)$, and $\mathrm{pDCs}(6.04 \pm 0.887$ $\left.\mathrm{pDCs} / \mathrm{mm}^{2}\right)$ in the TS compared to the IET area $\left(0.679 \pm 0.179 \mathrm{cDC} 1 \mathrm{~s} / \mathrm{mm}^{2}, 1.51 \pm 0.371\right.$ $\left.\mathrm{cDC} 2 \mathrm{~s} / \mathrm{mm}^{2}, 0.246 \pm 0.0436 \mathrm{pDCs} / \mathrm{mm}^{2}\right)$. These findings provide evidence that $\mathrm{cDC} 1 \mathrm{~s}$, cDC2s, and pDCs are cellular components of the PDAC immune contexture that are preferentially localized in the TS and may participate in the orchestration of antitumor immunity. 


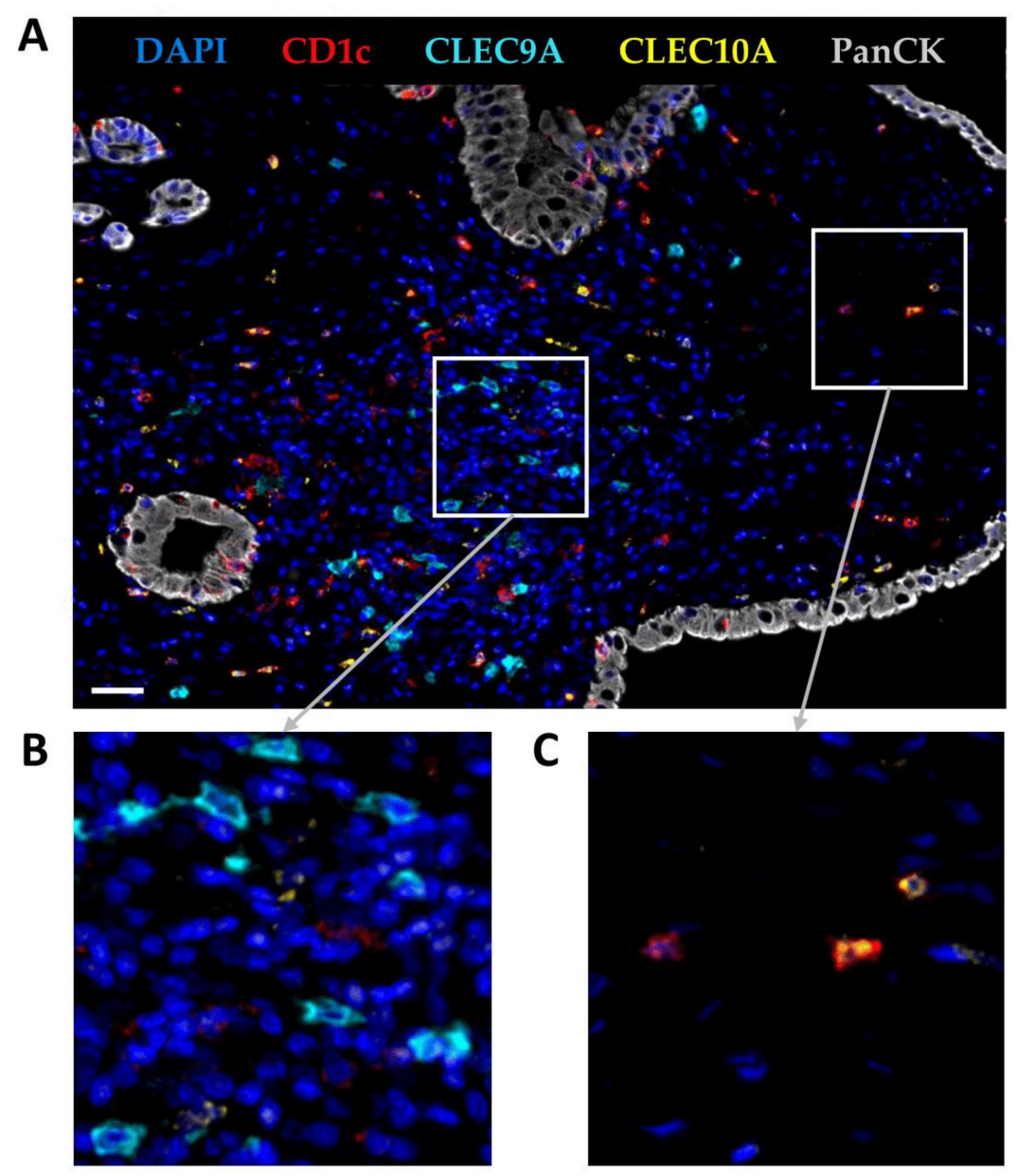

D

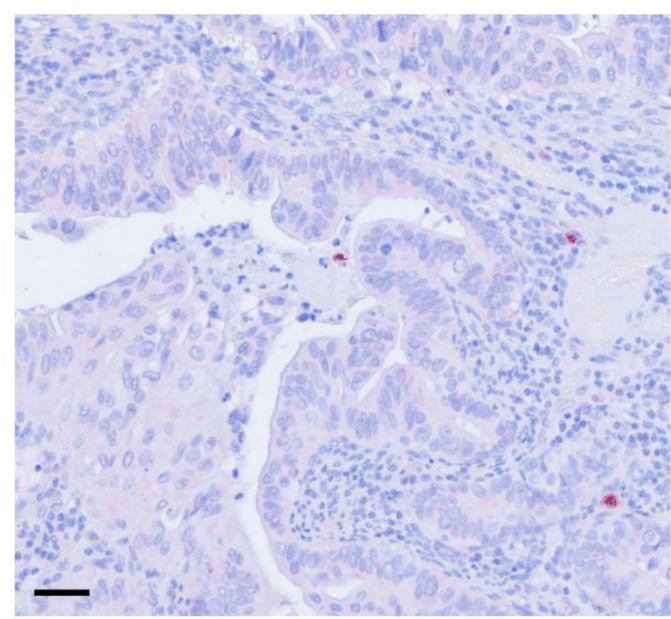

Figure 1. Conventional dendritic cells (DCs) type 1 (cDC1s) and type 2 (cDC2s), and plasmacytoid dendritic cells (pDCs) are cellular components of the pancreatic ductal adenocarcinoma (PDAC) immune architecture. (A-D) Immunohistochemical stainings were performed to assess the presence of tumor-infiltrating DCs. (A) Representative multiplex immunohistochemical staining of PDAC-infiltrating cDC1s (CLEC9A ${ }^{+}$cells) and cDC2s $\left(\mathrm{CD} 1 \mathrm{c}^{+} \mathrm{CLEC} 10 \mathrm{~A}^{+}\right.$cells) obtained by utilizing antibodies against CD1c (red), CLEC9A (yellow), CLEC10 (cyan), and PanCK (gray). Enlarged depictions of (B) cDC1s and (C) cDC2s. (D) Representative immunohistochemical staining of PDACinfiltrating $\mathrm{pDCs}\left(\mathrm{BDCA}^{+} 2^{+}\right.$cells). Original magnification of all images was $\times 200$. Scale bars indicate $50 \mu \mathrm{m}$. 
A

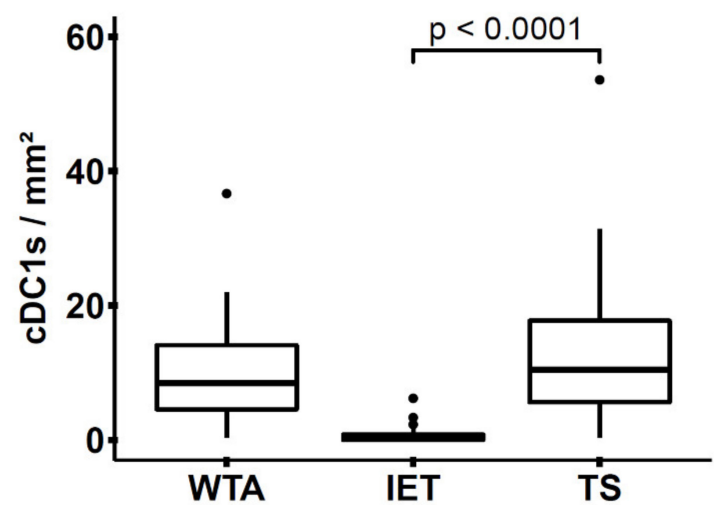

B

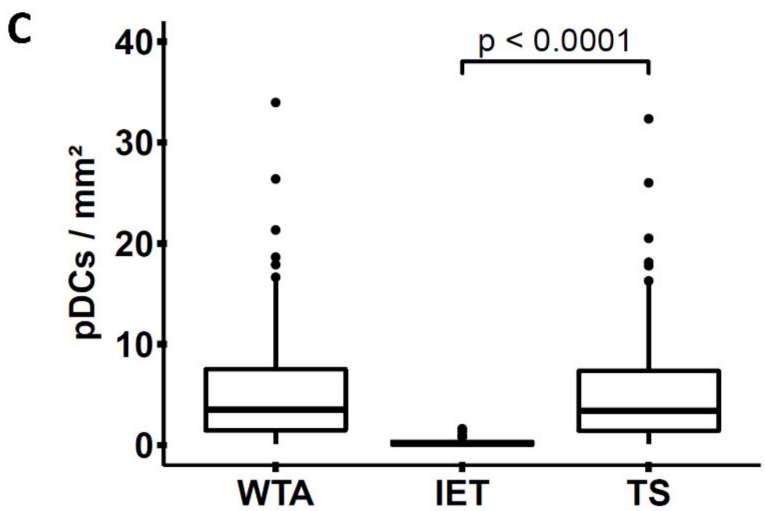

Figure 2. Frequency of pancreatic ductal adenocarcinoma (PDAC)-associated conventional dendritic cells (cDCs) and plasmacytoid dendritic cells (pDCs). Mean densities of PDAC-infiltrating (A) conventional DCs type 1 (cDC1s) $(n=40)$, (B) type 2 (cDC2s) $(n=40)$, and (C) plasmacytoid DCs (pDCs) $(n=58)$ were calculated for the whole tumor area (WTA), intraepithelial tumor area (IET), and tumor stroma (TS). Significance was determined by using paired Wilcoxon test, and $p \leq 0.05$ was considered significant.

3.2. Levels of PDAC-Infiltrating cDCs Correlate with Favorable Pathological Tumor Features and with Increased Survival of Patients

Next, we evaluated whether the density of tumor-associated cDC1s, cDC2s, and pDCs correlates with relevant clinicopathological characteristics of PDAC patients. We observed a higher infiltration of cDC1s into the IET area of patients with early pT1 tumor stage vs. pT2 and pT3 stages (Figure 3A), and of patients classified as UICC stage I compared to UICC stage II (Figure 3B). Similarly, a significantly higher density of cDC2s was found within the IET area of patients with pT1 stage (Figure 3C) and UICC stage I (Figure 3D). In contrast to cDCs, a lower pDC infiltration was detected in pT1 stage tumors compared to pT3 stage tumors (Figure 3E), while the density of pDCs remained unchanged between 
UICC stage I and II (Figure 3F). Furthermore, no other significant differences were detected in the frequencies of DCs within the WTA (Figure S1A-F) or TS (Figure S2A-F) across different $\mathrm{pT}$ and UICC stages. However, there was a trend toward an increased infiltration of cDC2s into the WTA (Figure S1D) and TS (Figure S2D) of patients classified as UICC stage I vs. stage II.

A

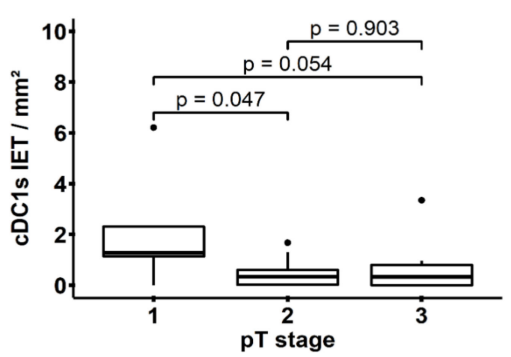

C

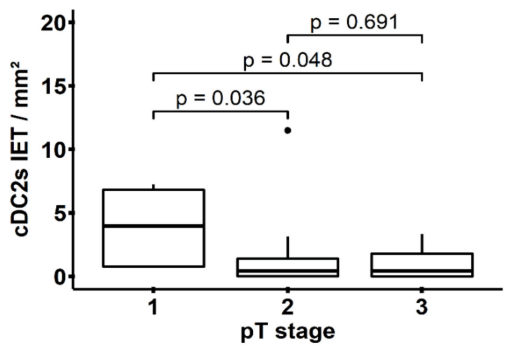

E

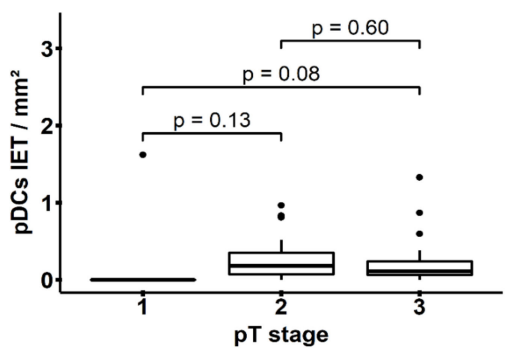

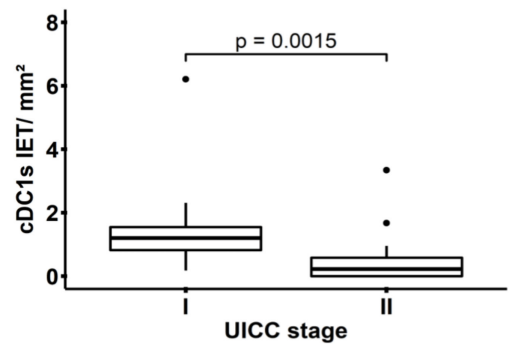

D

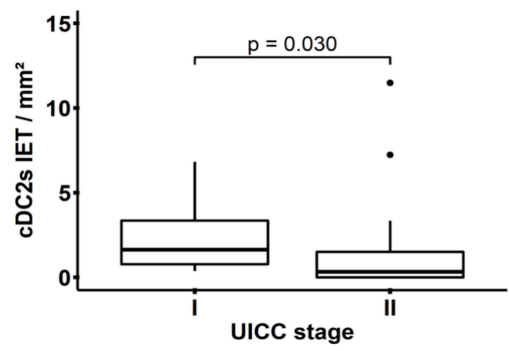

F

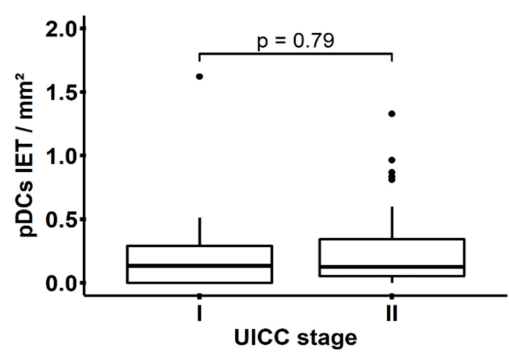

Figure 3. Frequency of intraepithelial tumor (IET) area-infiltrating dendritic cell (DC) subsets across distinct pathological tumor (pT) and Union for International Cancer Control (UICC) stages of pancreatic ductal adenocarcinoma (PDAC) patients. Boxplots show the density of IET-infiltrating conventional DCs type $1(\mathrm{cDC} 1 \mathrm{~s})(n=40)$, type 2 (cDC2s) $(n=40)$, and plasmacytoid DCs (pDCs) $(n=58)$ at different $(\mathbf{A}, \mathbf{C}, \mathbf{E})$ tumor stages or $(\mathbf{B}, \mathbf{D}, \mathbf{F})$ UICC stages. $p$ values were calculated using the Mann-Whitney $\mathrm{U}$ test, and $p \leq 0.05$ was considered significant.

In further studies, we explored the correlation between the density of PDAC-infiltrating DC subsets and the clinical outcome of patients (Figure 4A-L). A higher density of WTAand TS-infiltrating $\mathrm{CDC} 1 \mathrm{~s}$ was significantly associated with improved DFS in contrast to the IET-associated cDC1 frequency (Figure 4A-C). A trend for a correlation between an increased number of TS-infiltrating CDC1s and an improved OS was also observed, whereas the $\mathrm{CDC} 1$ density in the WTA and IET area did not influence OS (Figure 4D-F). As depicted in Figure 4G-L, a higher density of WTA-, IET-, and TS-infiltrating cDC2s was linked to better DFS and OS. Of note, the correlation between IET-infiltrating cDC2s and DFS or OS was significant (Figure $4 \mathrm{H}, \mathrm{K}$ ). When exploring the association between PDAC-infiltrating pDCs and the clinical outcome of patients, we found that an increased number of WTAand TS-infiltrating pDCs tended to be correlated with an improved DFS, whereas high densities of IET-infiltrating pDCs did not impact DFS (Figure 5A-C). Additionally, pDCs 
infiltration did not significantly influence OS, irrespective of localization (Figure 5D-F). These results indicate that a higher frequency of WTA- and TS-infiltrating CDC1s, as well as of IET-infiltrating $\mathrm{CDC} 2 \mathrm{~s}$, is significantly linked to better DFS.

A

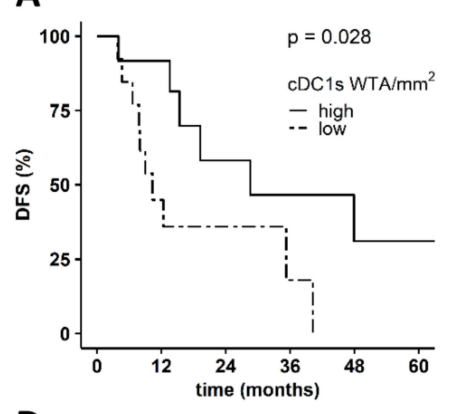

D

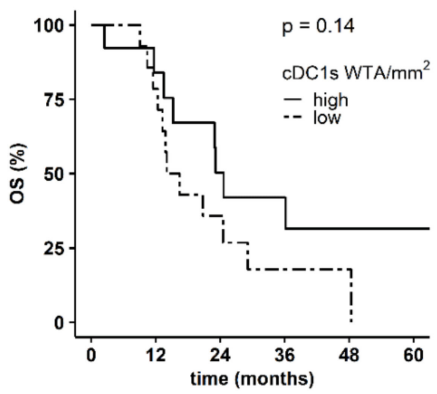

G

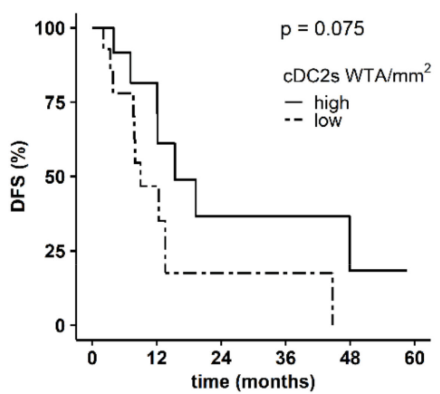

J

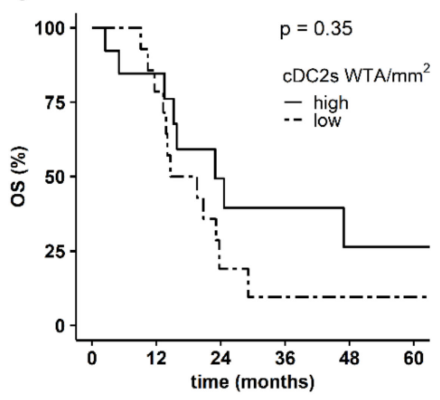

B

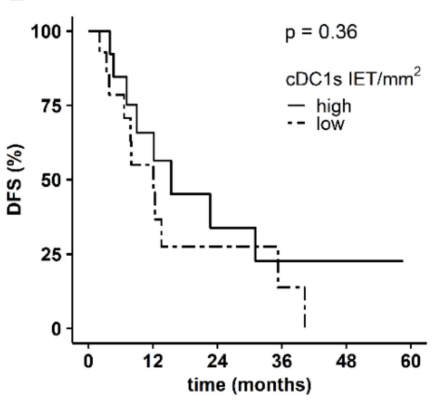

E

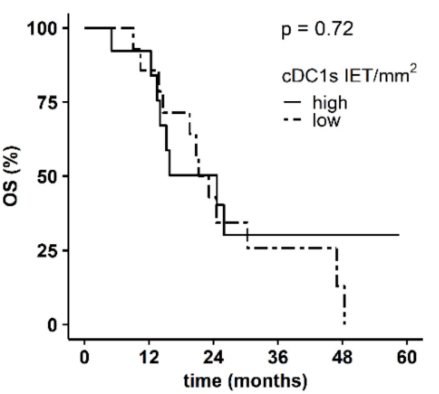

H

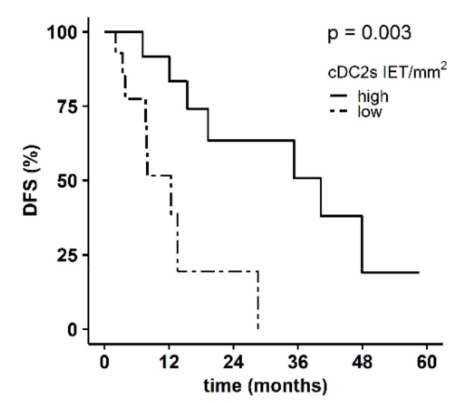

K

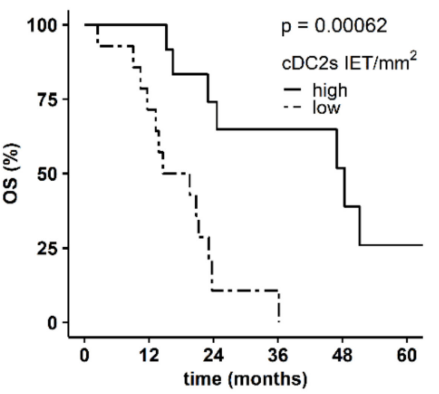

C

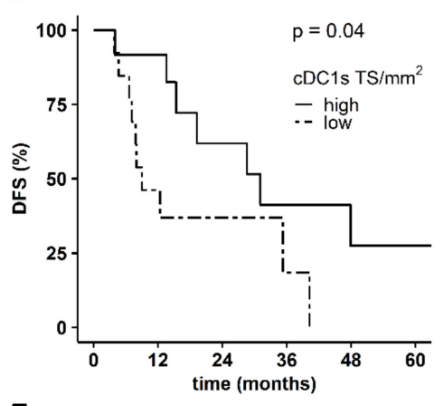

F

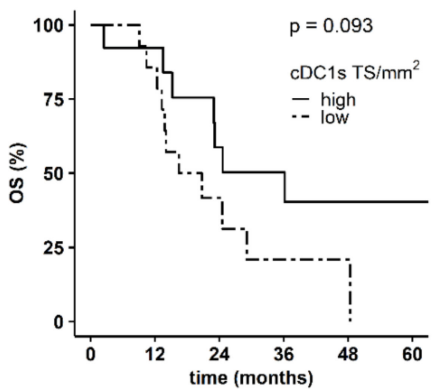

I

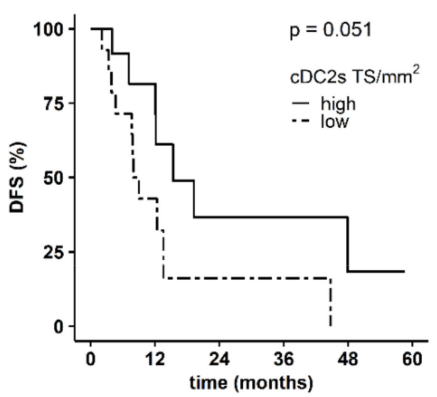

L

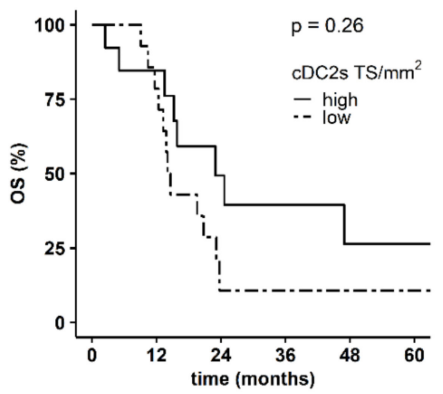

Figure 4. Association between the frequency of pancreatic ductal adenocarcinoma (PDAC)-infiltrating conventional dendritic cells (cDCs) and clinical outcome of patients. Kaplan-Meier curves illustrate the association between whole tumor area (WTA)-, intraepithelial tumor (IET)-, and tumor stroma (TS)-infiltrating cDCs type $1(\mathrm{cDC} 1 \mathrm{~s})(n=40)$ and $(\mathrm{A}-\mathrm{C})$ disease-free survival (DFS) or (D-F) overall survival (OS). Kaplan-Meier curves show the correlation between WTA-, IET-, and TS-infiltrating cDCs type $2(\mathrm{cDC} 2 \mathrm{~s})(n=40)$ and $(\mathbf{G}-\mathbf{I})$ DFS and $(\mathbf{J}-\mathbf{L})$ OS. Upper tercile (density $>2 / 3$ of the patients in the analyzed cohort; solid line) and lower tercile (density $\leq 1 / 3$ of patients in the analyzed cohort; dash line) were compared. $p$ values were calculated using the log-rank test, and $p \leq 0.05$ was considered significant. 
A

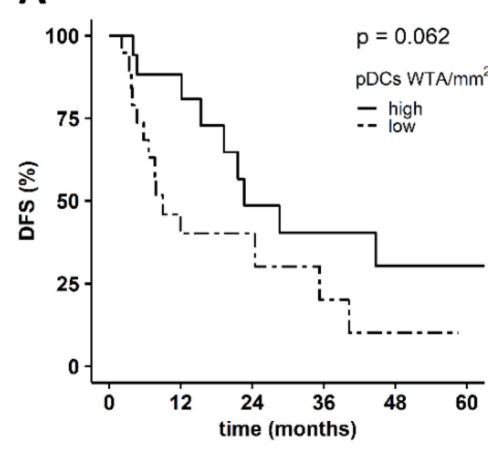

D

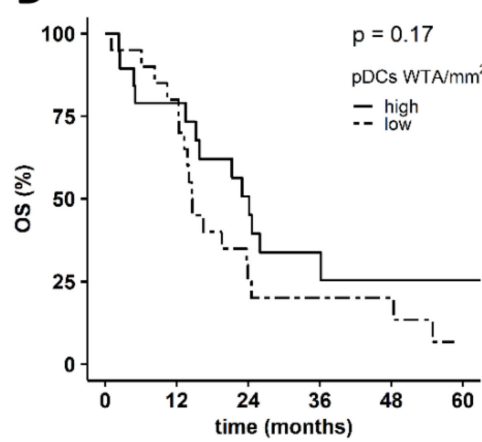

B

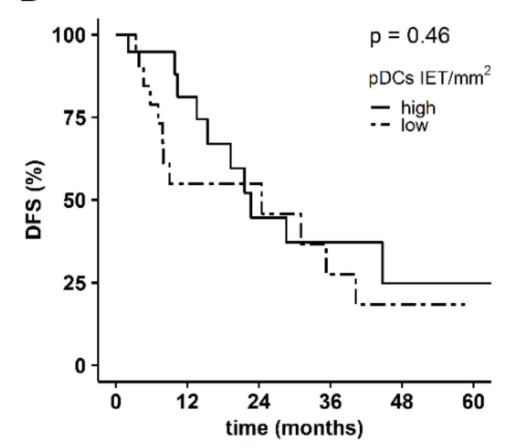

E

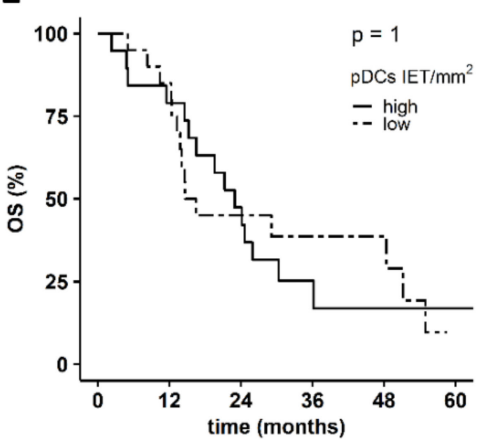

C

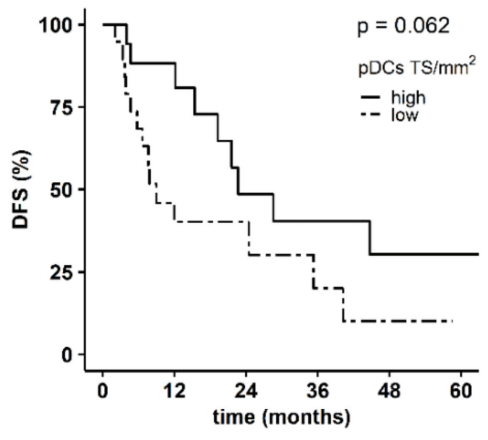

$\mathbf{F}$

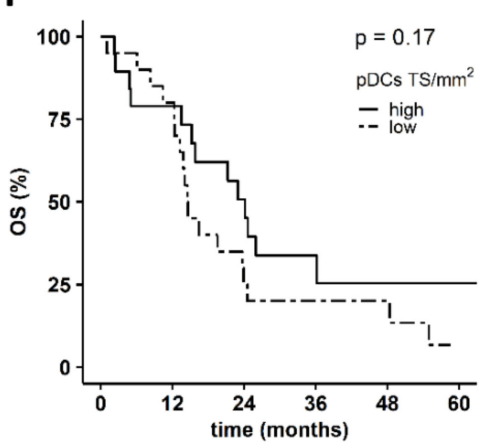

Figure 5. Association between the density of pancreatic ductal adenocarcinoma (PDAC)-infiltrating plasmacytoid dendritic cells (pDCs) and clinical outcome of patients. Kaplan-Meier curves illustrate the association between whole tumor area (WTA)-, intraepithelial tumor (IET)-, and tumor stroma (TS)-infiltrating pDCs $(n=58)$ and (A-C) disease-free survival (DFS) or (D-F) overall survival (OS). Upper tercile (density $>2 / 3$ of the patients in the analyzed cohort; solid line) and lower tercile (density $\leq 1 / 3$ of patients in the analyzed cohort; dash line) were compared. $p$ values were calculated using the log-rank test, and $p \leq 0.05$ was considered significant.

Based on these findings, we applied a multivariate Cox proportional hazard model to evaluate the prognostic relevance of PDAC-infiltrating DCs by adjusting for several clinicopathological characteristics, including age, gender, and tumor stage. From this analysis, we observed that a higher frequency of WTA- and TS-infiltrating cDC1s represents an independent prognostic factor for both DFS and OS in PDAC patients (Tables 2 and 3). Conversely, elevated levels of IET-infiltrating cDC1s and WTA-, IET-, and TS-infiltrating cDC2s did not show any prognostic significance for DFS and OS (Tables S1-S4). Furthermore, a higher density of WTA- and TS-infiltrating pDCs emerged as an independent prognostic factor for DFS, but not for OS (Tables 4 and 5). A higher density of IET-infiltrating pDCs did not show any prognostic value for DFS and OS (Table S5). Altogether, these findings provide evidence that PDAC-infiltrating $\mathrm{CDCs}$ are associated with the clinical outcome of the patients, and $\mathrm{CDC} 1 \mathrm{~s}$ and $\mathrm{pDCs}$ may represent novel prognostic biomarkers. 
Table 2. Higher densities of whole tumor area (WTA)-infiltrating conventional dendritic cells type 1 (cDC1s) are associated with favorable disease-free survival (DFS) and overall survival (OS). Hazard ratios (HR) and 95\% confidence intervals (CI) are shown.

\begin{tabular}{|c|c|c|c|c|}
\hline DFS-WTA & $n$ & HR & $95 \%$ CI & $p$-Value \\
\hline cDC1s & 40 & 0.89 & $0.82-0.97$ & $0.006^{* *}$ \\
\hline Age & 40 & 0.92 & $0.86-0.99$ & 0.017 * \\
\hline $\begin{array}{c}\text { Female vs. male } \\
\text { pT stage }\end{array}$ & 16 vs. 24 & 1.69 & $0.64-4.47$ & 0.294 \\
\hline pT2 vs. pT1 & 22 vs. 5 & 2.04 & $0.52-8.02$ & 0.306 \\
\hline $\begin{array}{l}\text { pT3 vs. pT1 } \\
\text { pN stage }\end{array}$ & 13 vs. 5 & 2.26 & $0.52-9.77$ & 0.273 \\
\hline pN1 vs. pN0 & 14 vs. 26 & 1.79 & $0.68-4.70$ & 0.239 \\
\hline \multicolumn{5}{|l|}{ OS-WTA } \\
\hline cDC1s & 40 & 0.92 & $0.85-0.98$ & 0.016 * \\
\hline Age & 40 & 0.96 & 0.91-1.01 & 0.094 \\
\hline $\begin{array}{c}\text { Female vs. male } \\
\text { pT stage }\end{array}$ & 16 vs. 24 & 1.70 & $0.74-3.93$ & 0.214 \\
\hline pT2 vs. pT1 & 22 vs. 5 & 5.41 & $0.67-43.51$ & 0.113 \\
\hline $\begin{array}{l}\text { pT3 vs. pT1 } \\
\text { pN stage }\end{array}$ & 13 vs. 5 & 3.77 & $0.46-31.09$ & 0.217 \\
\hline pN1 vs. pN0 & 14 vs. 26 & 2.88 & $1.28-6.50$ & $0.011 *$ \\
\hline
\end{tabular}

Abbreviations: $\mathrm{pT}$ : pathological tumor, $\mathrm{pN}$ : pathological node. $p \leq 0.05$ was considered significant. ${ }^{*} p \leq 0.05$ ** $p \leq 0.01$

Table 3. Higher frequencies of tumor stroma (TS)-infiltrating conventional dendritic cells type 1 (cDC1s) are correlated with better disease-free survival (DFS) and overall survival (OS). Hazard ratio (HR) and 95\% confidence intervals (CI) are shown.

\begin{tabular}{|c|c|c|c|c|}
\hline DFS-TS & $n$ & HR & $95 \%$ CI & $p$-Value \\
\hline cDC1s & 40 & 0.91 & $0.86-0.97$ & $0.005^{* *}$ \\
\hline Age & 40 & 0.91 & $0.85-0.98$ & $0.013 *$ \\
\hline $\begin{array}{c}\text { Female vs. male } \\
\text { pT stage }\end{array}$ & 16 vs. 24 & 1.84 & $0.67-5.04$ & 0.237 \\
\hline pT2 vs. pT1 & 22 vs. 5 & 1.88 & $0.49-7.26$ & 0.361 \\
\hline $\begin{array}{l}\text { pT3 vs. pT1 } \\
\text { pN stage }\end{array}$ & 13 vs. 5 & 1.98 & $0.46-8.55$ & 0.36 \\
\hline pN1 vs. pN0 & 14 vs. 26 & 1.83 & $0.70-4.84$ & 0.22 \\
\hline \multicolumn{5}{|l|}{ OS-TS } \\
\hline cDC1s & 40 & 0.93 & $0.88-0.98$ & $0.012 *$ \\
\hline Age & 40 & 0.95 & $0.90-1.01$ & 0.086 \\
\hline $\begin{array}{c}\text { Female vs. male } \\
\text { pT stage }\end{array}$ & 16 vs. 24 & 1.70 & $0.73-3.96$ & 0.22 \\
\hline pT2 vs. pT1 & 22 vs. 5 & 4.91 & $0.62-39.22$ & 0.133 \\
\hline $\begin{array}{l}\text { pT3 vs. pT1 } \\
\text { pN stage }\end{array}$ & 13 vs. 5 & 3.24 & $0.39-26.86$ & 0.277 \\
\hline pN1 vs. pN0 & 14 vs. 26 & 2.94 & $1.30-6.69$ & $0.01 * *$ \\
\hline
\end{tabular}

Abbreviations: pT: pathological tumor, $\mathrm{pN}$ : pathological node. $p \leq 0.05$ was considered significant. ${ }^{*} p \leq 0.05$, ** $p \leq 0.01$ 
Table 4. Higher densities of whole tumor area (WTA)-infiltrating plasmacytoid dendritic cells (pDCs) influence disease-free survival (DFS) but not overall survival (OS). Hazard ratio (HR) and 95\% confidence intervals $(\mathrm{CI})$ are shown. $p \leq 0.05$ was considered significant.

\begin{tabular}{|c|c|c|c|c|}
\hline DFS-WTA & $n$ & HR & $95 \%$ CI & $p$-Value \\
\hline pDCs & 58 & 0.90 & $0.82-0.98$ & $0.018 *$ \\
\hline Age & 58 & 0.94 & $0.90-0.99$ & $0.01 *$ \\
\hline $\begin{array}{c}\text { Female vs. male } \\
\text { pT stage }\end{array}$ & 28 vs. 30 & 1.38 & $0.61-3.12$ & 0.445 \\
\hline pT2 vs. pT1 & 33 vs. 5 & 1.74 & $0.47-6.46$ & 0.405 \\
\hline $\begin{array}{l}\text { pT3 vs. pT1 } \\
\text { pN stage }\end{array}$ & 20 vs. 5 & 2.97 & $0.74-11.91$ & 0.124 \\
\hline pN1 vs. pN0 & 35 vs. 23 & 3.08 & $1.35-7.03$ & $0.008^{* *}$ \\
\hline \multicolumn{5}{|l|}{ OS-WTA } \\
\hline pDCs & 58 & 0.95 & $0.89-1.0$ & 0.135 \\
\hline Age & 58 & 0.98 & 0.94-1.0 & 0.28 \\
\hline $\begin{array}{c}\text { Female vs. male } \\
\text { pT stage }\end{array}$ & 28 vs. 30 & 1.21 & $0.60-2.4$ & 0.587 \\
\hline pT2 vs. pT1 & 33 vs. 5 & 4.81 & $0.63-36.9$ & 0.13 \\
\hline $\begin{array}{l}\text { pT3 vs. pT1 } \\
\text { pN stage }\end{array}$ & 20 vs. 5 & 4.87 & $0.61-38.8$ & 0.135 \\
\hline pN1 vs. pN0 & 35 vs. 23 & 3.23 & $1.65-6.3$ & $<0.001 * * *$ \\
\hline
\end{tabular}

Table 5. Higher densities of tumor stroma (TS)-infiltrating plasmacytoid dendritic cells (pDCs) influence disease-free survival (DFS) but not overall survival (OS). Hazard ratio (HR) and 95\% confidence interval (CI) are shown. $p \leq 0.05$ was considered significant.

\begin{tabular}{|c|c|c|c|c|}
\hline DFS-TS & $n$ & HR & $95 \% \mathrm{CI}$ & $p \quad$ Value \\
\hline pDCs & 58 & 0.89 & $0.81-0.98$ & $0.017 *$ \\
\hline Age & 58 & 0.94 & $0.90-0.99$ & $0.01 *$ \\
\hline $\begin{array}{l}\text { Female vs. male } \\
\text { pT stage }\end{array}$ & \multicolumn{3}{|c|}{ pT stage } & 0.445 \\
\hline pT2 vs. pT1 & 33 vs. 5 & 1.74 & $0.47-6.46$ & 0.405 \\
\hline $\begin{array}{l}\text { pT3 vs. pT1 } \\
\text { pN stage }\end{array}$ & 20 vs. 5 & 2.98 & $0.74-11.95$ & 0.124 \\
\hline pN1 vs. pN0 & 35 vs. 23 & 3.08 & $1.35-7.04$ & $0.008 * *$ \\
\hline \multicolumn{5}{|l|}{ OS-TS } \\
\hline pDCs & 58 & 0.95 & $0.89-1.0$ & 0.144 \\
\hline Age & 58 & 0.98 & 0.94-1.0 & 0.276 \\
\hline $\begin{array}{c}\text { Female vs. male } \\
\text { pT stage }\end{array}$ & 28 vs. 30 & 1.21 & $0.60-2.4$ & 0.588 \\
\hline pT2 vs. pT1 & 33 vs. 5 & 4.79 & $0.63-36.7$ & 0.131 \\
\hline $\begin{array}{l}\text { pT3 vs. pT1 } \\
\text { pN stage }\end{array}$ & 20 vs. 5 & 4.82 & $0.61-38.3$ & 0.137 \\
\hline pN1 vs. pN0 & 35 vs. 23 & 3.21 & $1.65-6.3$ & $<0.001 * * *$ \\
\hline
\end{tabular}

\subsection{Neoadjuvant Chemotherapy Does Not Influence the Frequency of DCs in PDAC}

Recently, it has been demonstrated that chemotherapy can efficiently stimulate the antitumor immune response by triggering immunogenic cell death [39-41]. In contrast, chemotherapy can also induce immunosuppressive effects, including the increase in tumorpromoting MDSCs [41-43]. In addition, it has been reported that neoadjuvant chemotherapy results in an increased frequency of PDAC-infiltrating $\mathrm{CD}^{+}$and $\mathrm{CD}^{+} \mathrm{T}$ cells, while the density of Tregs and MDSCs decreases [44-47]. Following these findings, we explored the influence of neoadjuvant chemotherapy on the level of PDAC-associated DCs. As shown in Figure $6 \mathrm{~A}-\mathrm{C}$, neoadjuvant chemotherapy did not significantly modulate the frequency of PDAC-infiltrating $\mathrm{cDC} 1 \mathrm{~s}, \mathrm{cDC} 2 \mathrm{~s}$, and pDCs. 

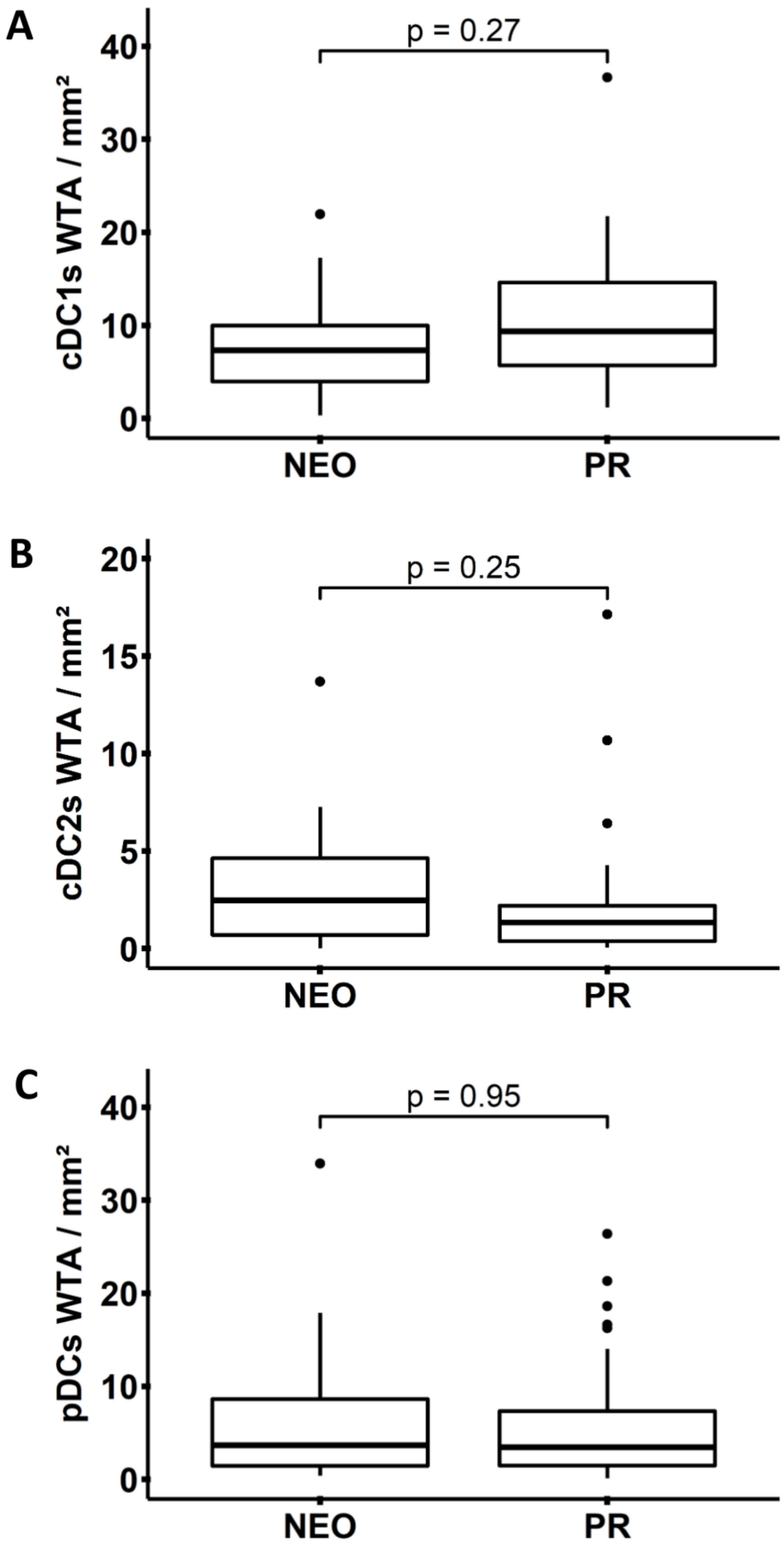

Figure 6. Effect of neoadjuvant chemotherapy (NEO) on the frequency of dendritic cells (DCs) within the whole tumor area (WTA) of pancreatic ductal adenocarcinoma (PDAC) patients. Boxplots show the frequencies of (A) conventional DCs type 1 (cDC1s) $(n=40)$, (B) type 2 (cDC2s) $(n=40)$, and $(C)$ plasmacytoid DCs (pDCs) $(n=58)$ in patients treated with NEO or primary resection (PR). Significances were tested using the Mann-Whitney $U$ test. $p \leq 0.05$ was considered significant. 


\section{Discussion}

The tumor immune architecture plays a crucial role for the clinical outcome of cancer patients and influences the efficacy of various treatment modalities [48-51]. In PDAC, we and other groups have shown that elevated levels of tumor-infiltrating $\mathrm{T}$ lymphocytes favored the prognosis of PDAC patients [52-56]. The spatial distribution of these cells is critical, as it has been reported that close proximity of $\mathrm{CD}^{+} \mathrm{T}$ cells to tumor cells favored OS [52]. The clinical impact of PDAC-infiltrating $\mathrm{T}$ lymphocytes has also been demonstrated in a recent report, indicating that a high Immunoscore, which is characterized by elevated densities of $\mathrm{CD}^{+}$and $\mathrm{CD}^{+} \mathrm{T}$ cells in both the tumor center and invasive margin, is significantly associated with better disease-specific survival (DSS) and OS [57]. In contrast, we have observed that a high infiltration of LAG $-3^{+} \mathrm{T}$ cells is a negative independent prognostic factor for DFS [54]. In addition, an increased density of Tregs was linked to worse clinical outcome, while a high frequency of intratumoral PD- $1^{+}$Tregs was correlated with lymph node metastasis $[53,58,59]$. When investigating macrophages as another major component of the tumor immune contexture, it has been shown that they mainly polarize toward an M2 phenotype in PDAC [60]. Additionally, a meta-analysis of PDAC-associated macrophages revealed that M2 macrophages are linked to unfavorable survival [61]. So far, only a few studies have evaluated other PDAC-infiltrating immune cell populations. Among them, it has been reported that high neutrophil counts negatively impact OS [55], whereas increased B-cell densities are associated with better survival [62]. The presence of B cells in the tumor-associated tertiary lymphoid structures, but not in the TS, favored patients' clinical outcome [63].

In contrast to $\mathrm{T}$ cells and macrophages, studies investigating the frequency, spatial organization, and clinical relevance of distinct human DC subsets in PDAC are very limited. DCs can essentially contribute to innate and adaptive antitumor immunity. In contrast, they can act as tolerogenic DCs by inhibiting tumor-directed immune responses. Hence, DCs may profoundly influence tumor development and progression, as well as clinical outcome. To gain novel insights into the role of DCs in pancreatic cancer, recent studies have used murine models. Thus, it has been shown that tumor-infiltrating CDCs are rare and dysfunctional and that enhancing the influx and activation of cDCs in established PDAC restores antitumor T-cell immunity, resulting in disease stabilization [64]. Furthermore, it has been reported that murine $\mathrm{CDC} 1 \mathrm{~s}$ are systemically dysregulated early in pancreatic cancer and that apoptosis of cDC1s mediated by IL- 6 essentially contributes to this effect [65]. In addition, it has been demonstrated that Tregs promote a tolerogenic phenotype of PDAC-associated CD11 $\mathrm{c}^{+}$DCs, leading to an insufficient activation of CD8 ${ }^{+}$CTLs [66]. Meyer et al. observed that granulocyte colony-stimulating factor produced by pancreatic cancer cells inhibits interferon regulatory factor-8 expression in cDCs progenitors, leading to reduced $\mathrm{cDC} 1$ generation and impaired antitumor $\mathrm{CD}^{+} \mathrm{T}$ cell responses [67]. Another recent study has reported that $\mathrm{CD} 11 \mathrm{~b}^{+} \mathrm{CD} 11 \mathrm{c}^{+} \mathrm{MHC}-\mathrm{II}^{+} \mathrm{CD} 24^{+} \mathrm{CD} 64^{\text {low }} \mathrm{F} 4 / 80^{\text {low }} \mathrm{DC}$ are an important component of PDAC-associated metastases that induce the expansion of Tregs and promote metastasis formation [68].

To explore the role of human DCs in PDAC, previous studies mainly evaluated the frequency and potential clinical impact of blood-circulating cDCs and pDCs. PDAC patients have reduced proportions of $\mathrm{CDCs}$ and pDCs in the blood compared to healthy donors [35-37,65]. In addition, it has been demonstrated that PDAC patients who survived longer had a higher percentage of circulating $\mathrm{cDCs}$ compared to those patients with shorter survival [35-37]. So far, only a few studies have investigated the density and clinical relevance of PDAC-infiltrating human DCs. When utilizing public databases, it has been shown that the density of activated DCs in PDAC tissues is significantly higher compared to para-tumor tissues [69]. Additionally, PDAC patients with early-stage tumors had significantly higher levels of tumor-infiltrating fascin ${ }^{+}$DCs compared to more advanced tumor stages. Moreover, an elevated density of tumor-infiltrating fascin ${ }^{+}$DCs was linked to improved survival of PDAC patients [37]. To gain novel insights into the clinical relevance of distinct human DC subsets in PDAC, we investigated the density and spatial organization 
of PDAC-associated cDC1s, cDC2s, and pDCs by utilizing mIHC and by evaluating their association with clinicopathological parameters. All three DC subsets were detectable in PDAC tissues and were preferentially located in the TS. The preferential localization of DCs in the TS was also previously shown in ovarian carcinoma, where mature DC-LAMP ${ }^{+}$ cells were mainly found in TS rather than in the IET area [70], as well as in breast cancer, where $\mathrm{CDC1}$ s were primarily located in the TS, close to $\mathrm{CD}^{+} \mathrm{T}$ lymphocytes [20]. Similarly, CD11 $\mathrm{c}^{+} \mathrm{cDC}$ s cells were significantly increased in the TS compared to the IET area in melanoma metastases [71]. In further experiments, we evaluated the clinical impact of the spatial organization of the three DC subsets within the PDAC tissues, given that the spatial distribution emerged as an important factor influencing patients' prognosis in previous studies. High densities of TS-infiltrating $\mathrm{CD}^{+} \mathrm{T}$ cells favored DSS of non-small-cell lung carcinoma patients, whereas their frequency in the tumor islands did not have any effect on DSS [72]. In contrast, an increased frequency of tumor island-associated CD3 ${ }^{+} \mathrm{T}$ cells was linked to improved relapse-free survival in triple negative breast cancer [73]. Here, we showed that in contrast to IET-infiltrating CDC1s, a higher density of TS-associated CDC1s was significantly correlated with prolonged DFS. These findings provide evidence that the density and spatial organization of PDAC-associated cDC1s, cDC2s, and pDCs play an important role for the clinical outcome of PDAC patients.

Taken together, we found that $\mathrm{cDC} 1 \mathrm{~s}, \mathrm{cDC} 2 \mathrm{~s}$, and pDCs were present in primary PDAC tissues at varying frequencies and were mainly located in the TS. Higher levels of IET-infiltrating cDC1s and cDC2s were detectable in pT1 and UICC I stages compared to higher stages. Moreover, elevated infiltration of cDC1s within the WTA and TS was significantly correlated with improved DFS. We also observed that an increased frequency of IET-infiltrating cDC2s was linked to better DFS and OS when performing Kaplan-Meier analysis, while a higher level of WTA- and TS-infiltrating pDCs tended to improve DFS. Moreover, a higher frequency of both WTA- and TS-infiltrating cDC1s and pDCs emerged as an independent prognostic factor for better DFS and OS. Additionally, neoadjuvant chemotherapy did not significantly influence the density of PDAC-infiltrating DCs.

\section{Conclusions}

These novel findings indicate that $\mathrm{cDC} 1 \mathrm{~s}, \mathrm{cDC} 2 \mathrm{~s}$, and $\mathrm{pDCs}$, as major human blood DC subsets, are components of the PDAC immune landscape. In addition, our results provide evidence that tumor-infiltrating DCs are associated with the survival of PDAC patients and that their density and spatial organization play an important role for the clinical outcome. PDAC-infiltrating cDC1s and pDCs may represent new independent prognostic markers for improved survival. Our data may also have implications for the generation of new treatment strategies that target PDAC-infiltrating DCs.

Supplementary Materials: The following supporting information can be downloaded at: https: / /www.mdpi.com/article/10.3390/cancers14051216/s1, Figure S1: Frequency of whole tumor area (WTA)-infiltrating dendritic cell (DC) subsets across distinct pathological tumor (pT) and Union for International Cancer Control (UICC) stages of pancreatic ductal adenocarcinoma (PDAC) patients, Figure S2: Frequency of tumor stroma (TS)-infiltrating dendritic cell (DC) subsets across distinct pathological tumor (pT) and Union for International Cancer Control (UICC) stages of pancreatic ductal adenocarcinoma (PDAC) patients, Table S1: Higher densities of intraepithelial tumor (IET)infiltrating conventional dendritic cells type $1(\mathrm{cDC1s})$ do not influence disease-free survival (DFS) and overall survival (OS), Table S2: Higher frequencies of whole tumor area (WTA)-infiltrating conventional dendritic cells type 2 (cDC2s) do not alter disease-free survival (DFS) and overall survival (OS), Table S3: Higher densities of intraepithelial tumor (IET)-infiltrating conventional dendritic cells type 2 (cDC2s) do not modulate disease-free survival (DFS) and overall survival (OS), Table S4: Higher frequencies of tumor stroma (TS)-infiltrating conventional dendritic cells type 2 (cDC2s) do not influence disease-free survival (DFS) and overall survival (OS), Table S5: Higher densities of intraepithelial tumor (IET)-infiltrating plasmacytoid dendritic cells (pDCs) do not alter disease-free survival (DFS) and overall survival (OS). 


\begin{abstract}
Author Contributions: Conceptualization, I.P., I.B. and M.S.; methodology, I.P., I.B., C.B., U.S., L.M., R.W. and D.A.; validation, L.S., A.M.S. and M.S.; formal analysis, L.S., A.M.S. and M.S.; investigation, I.P., I.B., C.B., U.S., L.M., R.W. and D.A.; resources, U.S., M.H., D.A., G.B., A.F., M.P.B., J.W., L.S. and A.M.S.; data curation, I.P. and I.B.; writing—original draft preparation, I.P. and I.B.; writing-review and editing, U.S., L.M., R.W., M.H., D.A., G.B., A.F., M.P.B., J.W., L.S., A.M.S. and M.S.; visualization, I.P. and I.B.; supervision, M.S.; project administration, I.P., I.B. and M.S. All authors have read and agreed to the published version of the manuscript.
\end{abstract}

Funding: This research was funded by the Federal Ministry of Education and Research (03ZU1111LA to A.F., 03ZU1111LB to M.P.B. and M.S. and 01ZX1913C to R.W.).

Institutional Review Board Statement: The study was conducted according to the guidelines of the Declaration of Helsinki and approved by the Institutional Review Board of the Faculty of Medicine of the TU Dresden (No EK446112017).

Informed Consent Statement: Informed consent was obtained from all patients involved in the study.

Data Availability Statement: The data presented in this study are available on request from the corresponding author.

Acknowledgments: We thank Susanne Doms for excellent technical assistance.

Conflicts of Interest: The authors declare no conflict of interest.

\title{
References
}

1. Siegel, R.L.; Miller, K.D.; Fuchs, H.E.; Jemal, A. Cancer statistics, 2021. CA Cancer J. Clin. 2021, 71, 7-33. [CrossRef] [PubMed]

2. Brezgyte, G.; Shah, V.; Jach, D.; Crnogorac-Jurcevic, T. Non-invasive biomarkers for earlier detection of pancreatic cancer-A comprehensive review. Cancers 2021, 13, 2722. [CrossRef]

3. Singh, R.R.; O’Reilly, E.M. New treatment strategies for metastatic pancreatic ductal adenocarcinoma. Drugs 2020, 80, 647-669. [CrossRef]

4. Christenson, E.S.; Jaffee, E.; Azad, N.S. Current and emerging therapies for patients with advanced pancreatic ductal adenocarcinoma: A bright future. Lancet Oncol. 2020, 21, e135-e145. [CrossRef]

5. Zhang, Y.; Zhang, Z. The history and advances in cancer immunotherapy: Understanding the characteristics of tumor-infiltrating immune cells and their therapeutic implications. Cell. Mol. Immunol. 2020, 17, 807-821. [CrossRef]

6. Principe, D.R.; Underwood, P.W.; Korc, M.; Trevino, J.G.; Munshi, H.G.; Rana, A. The current treatment paradigm for pancreatic ductal adenocarcinoma and barriers to therapeutic efficacy. Front. Oncol. 2021, 11, 2773. [CrossRef]

7. Ho, W.J.; Jaffee, E.M.; Zheng, L. The tumour microenvironment in pancreatic cancer-Clinical challenges and opportunities. Nat. Rev. Clin. Oncol. 2020, 17, 527-540. [CrossRef]

8. Awaji, M.; Singh, R.K. Cancer-associated fibroblasts' functional heterogeneity in pancreatic ductal adenocarcinoma. Cancers 2019, 11, 290. [CrossRef] [PubMed]

9. Wu, Y.; Zhang, C.; Jiang, K.; Werner, J.; Bazhin, A.V.; D’Haese, J.G. The role of stellate cells in pancreatic ductal adenocarcinoma: Targeting perspectives. Front. Oncol. 2021, 10, 3044. [CrossRef] [PubMed]

10. Sperb, N.; Tsesmelis, M.; Wirth, T. Crosstalk between tumor and stromal cells in pancreatic ductal adenocarcinoma. Int. J. Mol. Sci. 2020, 21, 5486. [CrossRef]

11. Wu, Q.; Tian, Y.; Zhang, J.; Zhang, H.; Gu, F.; Lu, Y.; Zou, S.; Chen, Y.; Sun, P.; Xu, M.; et al. Functions of pancreatic stellate cell-derived soluble factors in the microenvironment of pancreatic ductal carcinoma. Oncotarget 2017, 8, 102721-102738. [CrossRef] [PubMed]

12. Lunardi, S.; Jamieson, N.B.; Lim, S.Y.; Griffiths, K.L.; Carvalho-Gaspar, M.; Al-Assar, O.; Yameen, S.; Carter, R.C.; McKay, C.J.; Spoletini, G.; et al. IP-10/CXCL10 induction in human pancreatic cancer stroma influences lymphocytes recruitment and correlates with poor survival. Oncotarget 2014, 5, 11064-11080. [CrossRef] [PubMed]

13. Balachandran, V.P.; Beatty, G.L.; Dougan, S.K. Broadening the impact of immunotherapy to pancreatic cancer: Challenges and opportunities. Gastroenterology 2019, 156, 2056-2072. [CrossRef] [PubMed]

14. Wculek, S.K.; Cueto, F.J.; Mujal, A.M.; Melero, I.; Krummel, M.F.; Sancho, D. Dendritic cells in cancer immunology and immunotherapy. Nat. Rev. Immunol. 2020, 20, 7-24. [CrossRef]

15. Böttcher, J.P.; Reis e Sousa, C. The role of type 1 conventional dendritic cells in cancer immunity. Trends Cancer 2018, 4, 784-792. [CrossRef]

16. Del Prete, A.; Sozio, F.; Barbazza, I.; Salvi, V.; Tiberio, L.; Laffranchi, M.; Gismondi, A.; Bosisio, D.; Schioppa, T.; Sozzani, S. Functional role of dendritic cell subsets in cancer progression and clinical implications. Int. J. Mol. Sci. 2020, 21, 3930. [CrossRef] [PubMed]

17. Peterson, E.E.; Barry, K.C. The natural killer-dendritic cell immune axis in anti-cancer immunity and immunotherapy. Front. Immunol. 2021, 11, 3778. [CrossRef] 
18. Michea, P.; Noël, F.; Zakine, E.; Czerwinska, U.; Sirven, P.; Abouzid, O.; Goudot, C.; Scholer-Dahirel, A.; Vincent-Salomon, A.; Reyal, F.; et al. Adjustment of dendritic cells to the breast-cancer microenvironment is subset specific. Nat. Immunol. 2018, 19, 885-897. [CrossRef] [PubMed]

19. Böttcher, J.P.; Bonavita, E.; Chakravarty, P.; Blees, H.; Cabeza-Cabrerizo, M.; Sammicheli, S.; Rogers, N.C.; Sahai, E.; Zelenay, S.; Reis e Sousa, C. NK cells stimulate recruitment of cDC1 into the tumor microenvironment promoting cancer immune control. Cell 2018, 172, 1022-1037.e14. [CrossRef]

20. Hubert, M.; Gobbini, E.; Couillault, C.; Manh, T.V.; Doffin, A.-C.; Berthet, J.; Rodriguez, C.; Ollion, V.; Kielbassa, J.; Sajous, C.; et al. IFN-III is selectively produced by cDC1 and predicts good clinical outcome in breast cancer. Sci. Immunol. 2020, 5, 3942. [CrossRef]

21. Mattiuz, R.; Brousse, C.; Ambrosini, M.; Cancel, J.-C.; Bessou, G.; Mussard, J.; Sanlaville, A.; Caux, C.; Bendriss-Vermare, N.; Valladeau-Guilemond, J.; et al. Type 1 conventional dendritic cells and interferons are required for spontaneous CD4 ${ }^{+}$and $\mathrm{CD} 8^{+}$ T-cell protective responses to breast cancer. Clin. Transl. Immunol. 2021, 10, e1305. [CrossRef] [PubMed]

22. Mastelic-Gavillet, B.; Sarivalasis, A.; Lozano, L.E.; Wyss, T.; Inoges, S.; de Vries, I.J.M.; Dartiguenave, F.; Jichlinski, P.; Derrè, L.; Coukos, G.; et al. Quantitative and qualitative impairments in dendritic cell subsets of patients with ovarian or prostate cancer. Eur. J. Cancer 2020, 135, 173-182. [CrossRef] [PubMed]

23. Sosa Cuevas, E.; Ouaguia, L.; Mouret, S.; Charles, J.; De Fraipont, F.; Manches, O.; Valladeau-Guilemond, J.; Bendriss-Vermare, N.; Chaperot, L.; Aspord, C. BDCA $1^{+} \mathrm{cDC} 2 \mathrm{~s}, \mathrm{BDCA} 2^{+} \mathrm{pDC}$ and $\mathrm{BDCA} 3^{+} \mathrm{cDC} 1 \mathrm{~s}$ reveal distinct pathophysiologic features and impact on clinical outcomes in melanoma patients. Clin. Transl. Immunol. 2020, 9, e1190. [CrossRef] [PubMed]

24. Collin, M.; Bigley, V. Human dendritic cell subsets: An update. Immunology 2018, 154, 3-20. [CrossRef]

25. Rhodes, J.W.; Tong, O.; Harman, A.N.; Turville, S.G. Human dendritic cell subsets, ontogeny, and impact on HIV infection. Front. Immunol. 2019, 10, 1088. [CrossRef]

26. Tabarkiewicz, J.; Rybojad, P.; Jablonka, A.; Rolinski, J. CD1c ${ }^{+}$and CD303 ${ }^{+}$Dendritic cells in peripheral blood, lymph nodes and tumor tissue of patients with non-small cell lung cancer. Oncol. Rep. 2008, 19, 237-243. [CrossRef]

27. Jahrsdörfer, B.; Vollmer, A.; Blackwell, S.E.; Maier, J.; Sontheimer, K.; Beyer, T.; Mandel, B.; Lunov, O.; Tron, K.; Nienhaus, G.U.; et al. Granzyme B produced by human plasmacytoid dendritic cells suppresses T-cell expansion. Blood 2010, 115, 1156-1165. [CrossRef]

28. Kalb, M.L.; Glaser, A.; Stary, G.; Koszik, F.; Stingl, G. TRAIL(+) human plasmacytoid dendritic cells kill tumor cells in vitro: Mechanisms of imiquimod- and IFN- $\alpha$-mediated antitumor reactivity. J. Immunol. Baltim. Md 1950 2012, 188, $1583-1591$. [CrossRef]

29. Zhou, B.; Lawrence, T.; Liang, Y. The role of plasmacytoid dendritic cells in cancers. Front. Immunol. 2021, 12, 4414. [CrossRef]

30. Kießler, M.; Plesca, I.; Sommer, U.; Wehner, R.; Wilczkowski, F.; Müller, L.; Tunger, A.; Lai, X.; Rentsch, A.; Peuker, K.; et al. Tumor-infiltrating plasmacytoid dendritic cells are associated with survival in human colon cancer. J. Immunother. Cancer 2021, 9 , e001813. [CrossRef]

31. Treilleux, I.; Blay, J.-Y.; Bendriss-Vermare, N.; Ray-Coquard, I.; Bachelot, T.; Guastalla, J.-P.; Bremond, A.; Goddard, S.; Pin, J.-J.; Barthelemy-Dubois, C.; et al. Dendritic cell infiltration and prognosis of early-stage breast cancer. Clin. Cancer Res. 2004, 10, 7466-7474. [CrossRef]

32. Pang, L.; Ng, K.T.; Liu, J.; Yeung, W.O.; Zhu, J.; Chiu, T.S.; Liu, H.; Chen, Z.; Lo, C.-M.; Man, K. Plasmacytoid dendritic cells recruited by HIF-1 $\alpha /$ EADO/ADORA1 signaling induce immunosuppression in hepatocellular carcinoma. Cancer Lett. 2021, 522, 80-92. [CrossRef]

33. Aspord, C.; Leccia, M.-T.; Charles, J.; Plumas, J. Plasmacytoid dendritic cells support melanoma progression by promoting Th2 and regulatory immunity through OX40L and ICOSL. Cancer Immunol. Res. 2013, 1, 402-415. [CrossRef]

34. Labidi-Galy, S.I.; Treilleux, I.; Goddard-Leon, S.; Combes, J.-D.; Blay, J.-Y.; Ray-Coquard, I.; Caux, C.; Bendriss-Vermare, N. Plasmacytoid dendritic cells infiltrating ovarian cancer are associated with poor prognosis. OncoImmunology 2012, 1, 380-382. [CrossRef] [PubMed]

35. Hirooka, S.; Yanagimoto, H.; Satoi, S.; Yamamoto, T.; Toyokawa, H.; Yamaki, S.; Yui, R.; Inoue, K.; Michiura, T.; Kwon, A.-H. The role of circulating dendritic cells in patients with unresectable pancreatic cancer. Anticancer. Res. 2011, 31, 3827-3834.

36. Tjomsland, V.; Sandström, P.; Spångeus, A.; Messmer, D.; Emilsson, J.; Falkmer, U.; Falkmer, S.; Magnusson, K.-E.; Borch, K.; Larsson, M. Pancreatic adenocarcinoma exerts systemic effects on the peripheral blood myeloid and plasmacytoid dendritic cells: An indicator of disease severity? BMC Cancer 2010, 10, 87. [CrossRef] [PubMed]

37. Yamamoto, T.; Yanagimoto, H.; Satoi, S.; Toyokawa, H.; Yamao, J.; Kim, S.; Terakawa, N.; Takahashi, K.; Kwon, A.-H. Circulating myeloid dendritic cells as prognostic factors in patients with pancreatic cancer who have undergone surgical resection. J. Surg. Res. 2012, 173, 299-308. [CrossRef] [PubMed]

38. Brierley, J.D.; Gospodarowicz, M.K.; Wittekind, C. TNM Classification of Malignant Tumours, 8th ed.; WILEY Blackwell: Oxford, UK, 2017; pp. 126-129.

39. Opzoomer, J.W.; Sosnowska, D.; Anstee, J.E.; Spicer, J.F.; Arnold, J.N. Cytotoxic chemotherapy as an immune stimulus: A molecular perspective on turning up the immunological heat on cancer. Front. Immunol. 2019, 10, 1654. [CrossRef]

40. Obeid, M.; Tesniere, A.; Ghiringhelli, F.; Fimia, G.M.; Apetoh, L.; Perfettini, J.-L.; Castedo, M.; Mignot, G.; Panaretakis, T.; Casares, N.; et al. Calreticulin exposure dictates the immunogenicity of cancer cell death. Nat. Med. 2007, 13, 54-61. [CrossRef] 
41. Galluzzi, L.; Buqué, A.; Kepp, O.; Zitvogel, L.; Kroemer, G. Immunological effects of conventional chemotherapy and targeted anticancer agents. Cancer Cell 2015, 28, 690-714. [CrossRef]

42. Kwong, T.T.; Wong, C.H.; Zhou, J.Y.; Cheng, A.S.L.; Sung, J.J.Y.; Chan, A.W.H.; Chan, S.L. Chemotherapy-induced recruitment of myeloid-derived suppressor cells abrogates efficacy of immune checkpoint blockade. JHEP Rep. 2020, 3, 100224. [CrossRef] [PubMed]

43. Kanterman, J.; Sade-Feldman, M.; Biton, M.; Ish-Shalom, E.; Lasry, A.; Goldshtein, A.; Hubert, A.; Baniyash, M. Adverse immunoregulatory effects of 5FU and CPT11 chemotherapy on myeloid-derived suppressor cells and colorectal cancer outcomes Cancer Res. 2014, 74, 6022-6035. [CrossRef]

44. Michelakos, T.; Cai, L.; Villani, V.; Sabbatino, F.; Kontos, F.; Fernández-Del Castillo, C.; Yamada, T.; Neyaz, A.; Taylor, M.S.; Deshpande, V.; et al. Tumor microenvironment immune response in pancreatic ductal adenocarcinoma patients treated with neoadjuvant therapy. J. Natl. Cancer Inst. 2021, 113, 182-191. [CrossRef]

45. Peng, H.; James, C.A.; Cullinan, D.R.; Hogg, G.D.; Mudd, J.L.; Zuo, C.; Takchi, R.; Caldwell, K.E.; Liu, J.; DeNardo, D.G.; et al. Neoadjuvant FOLFIRINOX therapy is associated with increased effector T cells and reduced suppressor cells in patients with pancreatic cancer. Clin. Cancer Res. 2021, 27, 6761-6771. [CrossRef] [PubMed]

46. Mota Reyes, C.; Teller, S.; Muckenhuber, A.; Konukiewitz, B.; Safak, O.; Weichert, W.; Friess, H.; Ceyhan, G.O.; Demir, I.E. Neoadjuvant therapy remodels the pancreatic cancer microenvironment via depletion of protumorigenic immune cells. Clin. Cancer Res. 2020, 26, 220-231. [CrossRef]

47. Shibuya, K.C.; Goel, V.K.; Xiong, W.; Sham, J.G.; Pollack, S.M.; Leahy, A.M.; Whiting, S.H.; Yeh, M.M.; Yee, C.; Riddell, S.R.; et al. Pancreatic ductal adenocarcinoma contains an effector and regulatory immune cell infiltrate that is altered by multimodal neoadjuvant treatment. PLoS ONE 2014, 9, e96565. [CrossRef]

48. Binnewies, M.; Roberts, E.W.; Kersten, K.; Chan, V.; Fearon, D.F.; Merad, M.; Coussens, L.M.; Gabrilovich, D.I.; Ostrand-Rosenberg, S.; Hedrick, C.C.; et al. Understanding the tumor immune microenvironment (TIME) for effective therapy. Nat. Med. 2018, 24, 541-550. [CrossRef] [PubMed]

49. Fridman, W.H.; Zitvogel, L.; Sautès-Fridman, C.; Kroemer, G. The immune contexture in cancer prognosis and treatment. Nat. Rev. Clin. Oncol. 2017, 14, 717-734. [CrossRef]

50. Galon, J.; Bruni, D. Tumor immunology and tumor evolution: Intertwined histories. Immunity 2020, 52, 55-81. [CrossRef] [PubMed]

51. Bruni, D.; Angell, H.K.; Galon, J. The immune contexture and immunoscore in cancer prognosis and therapeutic efficacy. Nat. Rev. Cancer 2020, 20, 662-680. [CrossRef]

52. Carstens, J.L.; Correa de Sampaio, P.; Yang, D.; Barua, S.; Wang, H.; Rao, A.; Allison, J.P.; LeBleu, V.S.; Kalluri, R. Spatial computation of intratumoral T cells correlates with survival of patients with pancreatic cancer. Nat. Commun. 2017, 8, 15095. [CrossRef]

53. Kiryu, S.; Ito, Z.; Suka, M.; Bito, T.; Kan, S.; Uchiyama, K.; Saruta, M.; Hata, T.; Takano, Y.; Fujioka, S.; et al. Prognostic value of immune factors in the tumor microenvironment of patients with pancreatic ductal adenocarcinoma. BMC Cancer 2021, $21,1197$. [CrossRef] [PubMed]

54. Seifert, L.; Plesca, I.; Müller, L.; Sommer, U.; Heiduk, M.; von Renesse, J.; Digomann, D.; Glück, J.; Klimova, A.; Weitz, J.; et al. LAG-3-expressing tumor-infiltrating T cells are associated with reduced disease-free survival in pancreatic cancer. Cancers 2021, 13, 1297. [CrossRef]

55. Tang, R.; Liu, X.; Liang, C.; Hua, J.; Xu, J.; Wang, W.; Meng, Q.; Liu, J.; Zhang, B.; Yu, X.; et al. Deciphering the prognostic implications of the components and signatures in the immune microenvironment of pancreatic ductal adenocarcinoma. Front. Immunol. 2021, 12, 575. [CrossRef]

56. Mahajan, U.M.; Langhoff, E.; Goni, E.; Costello, E.; Greenhalf, W.; Halloran, C.; Ormanns, S.; Kruger, S.; Boeck, S.; Ribback, S.; et al. Immune cell and stromal signature associated with progression-free survival of patients with resected pancreatic ductal adenocarcinoma. Gastroenterology 2018, 155, 1625-1639.e2. [CrossRef]

57. Tahkola, K.; Mecklin, J.-P.; Wirta, E.-V.; Ahtiainen, M.; Helminen, O.; Böhm, J.; Kellokumpu, I. High immune cell score predicts improved survival in pancreatic cancer. Virchows Arch. 2018, 472, 653-665. [CrossRef] [PubMed]

58. Wartenberg, M.; Zlobec, I.; Perren, A.; Koelzer, V.H.; Gloor, B.; Lugli, A.; Karamitopoulou, E. Accumulation of FOXP3 ${ }^{+}$T-cells in the tumor microenvironment is associated with an epithelial-mesenchymal-transition-type tumor budding phenotype and is an independent prognostic factor in surgically resected pancreatic ductal adenocarcinoma. Oncotarget 2015, 6, 4190-4201. [CrossRef]

59. Seifert, A.M.; Eymer, A.; Heiduk, M.; Wehner, R.; Tunger, A.; von Renesse, J.; Decker, R.; Aust, D.E.; Welsch, T.; Reissfelder, C.; et al. PD-1 expression by lymph node and intratumoral regulatory $\mathrm{T}$ cells is associated with lymph node metastasis in pancreatic cancer. Cancers 2020, 12, 2756. [CrossRef] [PubMed]

60. Yang, S.; Liu, Q.; Liao, Q. Tumor-associated macrophages in pancreatic ductal adenocarcinoma: Origin, polarization, function, and reprogramming. Front. Cell Dev. Biol. 2021, 8, 607209. [CrossRef]

61. Yu, M.; Guan, R.; Hong, W.; Zhou, Y.; Lin, Y.; Jin, H.; Hou, B.; Jian, Z. Prognostic value of tumor-associated macrophages in pancreatic cancer: A meta-analysis. Cancer Manag. Res. 2019, 11, 4041-4058. [CrossRef]

62. Brunner, M.; Maier, K.; Rümmele, P.; Jacobsen, A.; Merkel, S.; Benard, A.; Krautz, C.; Kersting, S.; Grützmann, R.; Weber, G.F. Upregulation of CD20 positive B-cells and B-cell aggregates in the tumor infiltration zone is associated with better survival of patients with pancreatic ductal adenocarcinoma. Int. J. Mol. Sci. 2020, 21, 1779. [CrossRef] [PubMed] 
63. Castino, G.F.; Cortese, N.; Capretti, G.; Serio, S.; Di Caro, G.; Mineri, R.; Magrini, E.; Grizzi, F.; Cappello, P.; Novelli, F.; et al. Spatial distribution of B cells predicts prognosis in human pancreatic adenocarcinoma. OncoImmunology 2015, 5, e1085147. [CrossRef] [PubMed]

64. Hegde, S.; Krisnawan, V.E.; Herzog, B.H.; Zuo, C.; Breden, M.A.; Knolhoff, B.L.; Hogg, G.D.; Tang, J.P.; Baer, J.M.; Mpoy, C.; et al. Dendritic cell paucity leads to dysfunctional immune surveillance in pancreatic cancer. Cancer Cell 2020, 37, 289-307.e9. [CrossRef]

65. Lin, J.H.; Huffman, A.P.; Wattenberg, M.M.; Walter, D.M.; Carpenter, E.L.; Feldser, D.M.; Beatty, G.L.; Furth, E.E.; Vonderheide, R.H. Type 1 conventional dendritic cells are systemically dysregulated early in pancreatic carcinogenesis. J. Exp. Med. 2020, 217, e20190673. [CrossRef] [PubMed]

66. Jang, J.-E.; Hajdu, C.H.; Liot, C.; Miller, G.; Dustin, M.L.; Bar-Sagi, D. Crosstalk between regulatory T cells and tumor-associated dendritic cells negates anti-tumor immunity in pancreatic cancer. Cell Rep. 2017, 20, 558-571. [CrossRef]

67. Meyer, M.A.; Baer, J.M.; Knolhoff, B.L.; Nywening, T.M.; Panni, R.Z.; Su, X.; Weilbaecher, K.N.; Hawkins, W.G.; Ma, C.; Fields, R.C.; et al. Breast and pancreatic cancer interrupt IRF8-dependent dendritic cell development to overcome immune surveillance. Nat. Commun. 2018, 9, 1250. [CrossRef]

68. Kenkel, J.A.; Tseng, W.W.; Davidson, M.G.; Tolentino, L.L.; Choi, O.; Bhattacharya, N.; Seeley, E.S.; Winer, D.A.; Reticker-Flynn, N.E.; Engleman, E.G. An immunosuppressive dendritic cell subset accumulates at secondary sites and promotes metastasis in pancreatic cancer. Cancer Res. 2017, 77, 4158-4170. [CrossRef]

69. Xu, C.; Sui, S.; Shang, Y.; Yu, Z.; Han, J.; Zhang, G.; Ntim, M.; Hu, M.; Gong, P.; Chen, H.; et al. The landscape of immune cell infiltration and its clinical implications of pancreatic ductal adenocarcinoma. J. Adv. Res. 2020, 24, 139-148. [CrossRef]

70. Truxova, I.; Kasikova, L.; Hensler, M.; Skapa, P.; Laco, J.; Pecen, L.; Belicova, L.; Praznovec, I.; Halaska, M.J.; Brtnicky, T.; et al. Mature dendritic cells correlate with favorable immune infiltrate and improved prognosis in ovarian carcinoma patients. $J$. Immunother. Cancer 2018, 6, 139. [CrossRef]

71. Halse, H.; Colebatch, A.J.; Petrone, P.; Henderson, M.A.; Mills, J.K.; Snow, H.; Westwood, J.A.; Sandhu, S.; Raleigh, J.M.; Behren, A.; et al. Multiplex immunohistochemistry accurately defines the immune context of metastatic melanoma. Sci. Rep. 2018, 8, 11158. [CrossRef]

72. Al-Shibli, K.I.; Donnem, T.; Al-Saad, S.; Persson, M.; Bremnes, R.M.; Busund, L.-T. Prognostic effect of epithelial and stromal lymphocyte infiltration in non-small cell lung cancer. Clin. Cancer Res. 2008, 14, 5220-5227. [CrossRef] [PubMed]

73. Wortman, J.C.; He, T.-F.; Solomon, S.; Zhang, R.Z.; Rosario, A.; Wang, R.; Tu, T.Y.; Schmolze, D.; Yuan, Y.; Yost, S.E.; et al. Spatial distribution of B cells and lymphocyte clusters as a predictor of triple-negative breast cancer outcome. Npj Breast Cancer 2021, 7, 1-13. [CrossRef] [PubMed] 